\title{
Quality-driven framework for reducing patient waiting time in emergency department
}

\author{
Neven Saleh*, Hend Adel** and Manal Abdel Wahed** \\ *Systems and Biomedical Engineering Department, Higher Institute of Engineering in El-Shorouk City, Cairo, Egypt \\ **Systems and Biomedical Engineering Department, Faculty of Engineering, Cairo University, Giza, Egypt \\ *Corresponding Author: nevensaleh76@gmail.com
}

Submitted: $11 / 10 / 2019$

Revised: $10 / 11 / 2019$

Accepted: 04/12/2019

\begin{abstract}
Emergency department is the first admission point for urgent patients. It is characterized by the overcrowding due to the functional operations of this department. Indeed, sometimes one minute for an emergency department patient means life sustainability. One form to cope with the overcrowding problem is to reduce patient waiting time. Therefore, the study aims to reduce the average waiting time for all types of emergency department patients by using quality function deployment. It starts with involvement of all stakeholders within the department. The stakeholders include patients, nurses, doctors, and clinical engineers. The framework was designed through six steps, commencing with customer (patients) requirements identification, and concluding with the weights of technical requirements. The model has been applied on 2 hospitals. Paired samples t-test results reveal a significant reduction in the average waiting time, increasing the served patients and improving the quality of emergency department services. The main contribution of this article is utilizing the quality function deployment as a new methodology in resolving the overcrowding problem in emergency department.
\end{abstract}

Keywords: Patient; waiting time; overcrowding; emergency department; quality function deployment.

\section{INTRODUCTION}

Overcrowding is a dominant feature of emergency departments (ED) worldwide. The underlying reasons vary depending on nature of the healthcare facility. The reasons comprise long duration of patient admission in triage area, shortage of medical staff, shortage of beds, slow procedures of radiology and laboratory tests, and long waiting time of patients (Adel et al., 2018). Obviously, increasing numbers of the patients inside ED lead to severe consequences including delay of patient's treatment, dissatisfaction of medical staff and patients, increasing number of medical errors, and increasing rate of mortality (Chen-Mei et al., 2019). Therefore, it is essential to have a system that ensures a timely treatment of the patients rather than their attendance without clinical needs fulfilment. It should provide a tangible solution that improves quality of care.

In response to the problem of ED overcrowding, many studies were conducted to cope with this obstacle. In 2016, Ministry of Health and Welfare (MOHW) in Taiwan has launched a project, called Quality Improvement Project (QIP) (Chen-Mei et al., 2019). The goal of the project was to reduce the proportion of patient with a length of stay (LOS) over $48 \mathrm{~h}$ to be $0 \%$ in 2017. In implementation, 3 action plans were initiated: changing the architecture of patients transfer entries and exits, reevaluating the patients with LOS more than $32 \mathrm{~h}$ after the morning shift, and increasing the turnover rate of beds. As a result, the proportion of LOS over $48 \mathrm{~h}$ has decreased from $4.9 \%$ to $3.7 \%$.

In another study (Al-Refaie et al., 2014), patient's average waiting time in ED was reduced by improving configuration of nurses assignment. The study has applied Decision Making Unit (DMU) as a simulation technique 
for assignment of nurses. Further, Data Envelopment Analysis (DEA) technique was adopted to measure the relative efficiency of DMU. The model was developed through six steps to minimize the average waiting time of patients and to maximize the number of served patients as well as the number of nurses. Indeed, the model succeeded to improve the performance of ED in a sample of Jordanian hospitals. Patient waiting time was reduced from $195 \mathrm{~min}$ to $183 \mathrm{~min}$, and nurses' utilization was improved by $10 \%$.

Paul and Lin developed a generic model by presenting a simulation model for ED operations (Paul et al., 2012). Discrete Event Simulation (DES) was used to build the model through five phases. In phase 1, a deep insight into all ED operations was given. This includes processes of flow diagram, classification of activities, and assigning internal and/ or external ED status to the activities and processes. DES model has been developed in phase 2. In phase 3, the validity of DES model was tested to examine reliability of the strategy. Phase 4 involved studying the improvements on patient throughput and waiting time. Based on results of improvements, appropriate recommendations were determined. The fifth and last phase was the implementation of the concluded recommendations. In application, ProModel (Orem, UT) simulation software was used in this study. The results pointed to reduction of patient LOS by $18 \%$ when the number of physicians increased.

A type of simulation optimization model of ED unit has been developed in Kuwait (Ahmed et al., 2009). The aim of the study was to choose the best configuration of healthcare servers to optimize patient throughput. The overall activities of ED were simulated using DES. System simulation was described by the incoming parameters: i) arrival process to the receptionist; ii) arrival process to the examination room; iii) the routing probabilities of patients; iv) the number of servers at each stage; $v$ ) the type of service time distribution. Optimization has been carried out to maximize patient throughput (patient dismissed per unit time) and minimize average patient waiting time subjected to budget constraints. The optimization simulation model has provided an optimal staffing allocation that increased patient throughput by $28 \%$ and reduced average patient waiting time (category 1 ) by $40 \%$.

In another relevant study, a simulation model was developed in order to evaluate the quality of care in emergency department (Zeng et al., 2012). The ED services were assessed in terms of patient waiting time, LOS, and patient elopement. The model was developed based on patient flow within the ED and the layout of ED rooms. Results of the work suggested increasing the number of nurses, and additional computed tomography was recommended. By regarding design of the ED, Abdelsamad et al. presented another work that relied on involving the ED stakeholders in the design process (Abdelsamad et al., 2018). Stakeholders' requirements are compared with international standards to find out the gap between them. Further, a hybrid model was proposed by using the quality function deployment to prioritize ED functional units that should be highlighted. The model was applied on 2 hospitals at 2 different countries. The study recommended that international design standards should incorporate ED stakeholders' views to reflect their thoughts in the design.

The aim of this study was to resolve the problem of ED overcrowding by reducing patient waiting time. The quality function deployment (QFD) has been proposed through a set of criteria in order to explore the reality of Egyptian hospitals. It is a new approach to tackle this problem; it gives a reasonable weight for each cause. Accordingly, the QFD identifies ranking of causes that denote how we can overcome them.

The article is organized as follows. A background of the QFD is given in section 2. The methodology is presented and described in detail in section 3. Section 4 involves results of the study. Finally, section 5 concludes the work.

\section{BACKGROUND}

Design for Six Sigma (DFSS) is a complement of Six Sigma. It concerns on redesigning or developing products and/or services instead of enhancing the existing ones (Gremyr et al., 2013). One of the commonly used tools of DFSS is Quality Function Deployment (QFD). The policy of QFD is to transform customer's requirements into appropriate actions to fulfil customer satisfaction. In fact, the QFD has been applied for different domains (Dehe et al., 2017). In sense, application of the QFD in healthcare domain is slightly different from other domains in terms of identifying customer requirements and implementation (Gremyr et al., 2013). 
Typically, the QFD development process uses four linked matrices to present and exchange information phase by phase (Dehe et al., 2017; Saleh et al., 2015). The four linked matrices involve House of Quality (HoQ) matrix, design matrix, planning matrix, and production matrix (Bennur et al., 2012). Commonly, the HoQ is used in the QFD process especially for services development. In HoQ matrix, the Voice of Customers (VoC), namely, WHATs, is captured and presented as input design. On the other side, the Voice of Engineers (VoE), namely, HOWs, is collected to meet customer requirements. The HoQ development assumes a linear relationship between WHATs and HOWs (Dehe et al., 2017).

Adapted from relevant studies (Saleh et al., 2015; Delegado et al., 2007), six steps are initiated for establishing HoQ as shown in Fig. 1.

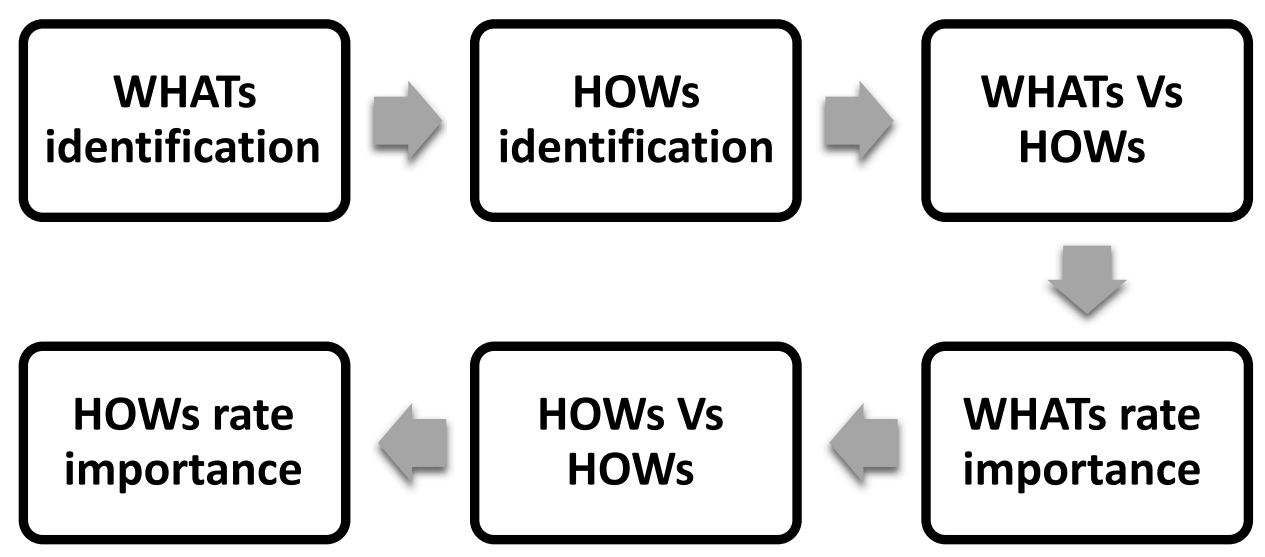

Fig. 1. Six stages framework for developing the QFD process.

In step 1, customer requirements (WHATs) are identified. Step 2 captures VoE, i.e., technical requirements (HOWs) that address customer requirements. The relationship between WHATs and HOWs is assigned in step 3. Step 4 rates the customer requirements importance by calculating absolute and relative weights of WHATs. Tradeoffs and correlations of technical requirements (VoE) are carried out in step 5. In step 6, the importance of technical requirements (HOWs) is rated by calculating the absolute and relative weights of HOWs.

The output of HoQ is the output of step 6, i.e., weights of HOWs. Therefore, all calculations in the QFD are carried out in steps 4 and 6, respectively. In step 4, absolute and relative weights for each customer requirement are calculated as follows.

- Give importance score (from 1 to 5).

- Give actual evaluation score (from 1 to 5).

- Identify the goal, i.e., targeted value (from 1 to 5).

- Determine improvement ratio by dividing the goal to the actual evaluation.

- Determine the absolute weight through multiplying the importance score by improvement ratio.

- Determine the relative weight by dividing the absolute weight to summation of all absolute weights (normalization).

On the other hand, the absolute weights of technical requirements are calculated as given in Equation (1). The relative weights are determined by normalizing the absolute weights, where id WHAT is the relative weight of each WHAT for $m$ WHATs, and $R W H$ is the relationship value between each WHAT and HOW. 


\section{METHODOLOGY}

The methodology of QFD has previously proven its ability to improve quality of care in accident and emergency unit in a Maltese hospital (Buttigieg et al., 2016). Therefore, QFD was proposed to reduce patient waiting time inside ED. The framework has developed through the six steps as mentioned above. The description and explanation of every step are presented in the next subsections.

\section{Customer requirements identification}

First, we need to identify the customers of this issue. No doubt, the patient is the customer of this service. According to the purpose of this research, it is considered as an action research (Gilmore et al., 1986). It means that all required information should be gathered from all stakeholders. From this point, informal discussions were made with patients in a governmental Egyptian hospital. In addition, the study of Buttigieg (Buttigieg et al., 2016) was considered. The authors classified customers' requirements into three classes: resources availability, service availability, and cost availability. Table 1 clarifies the classes of customer requirements with a total of 14 criteria. Resources availability involves 6 criteria, and service availability contains 7 criteria; meanwhile, cost availability was only cost of service.

Table 1. List of customer requirements in terms of resources, service, and cost.

\begin{tabular}{|c|c|c|}
\hline Resources Availability & Service Availability & Cost Availability \\
\hline 24-hour availability of staff & Better patient flow & \\
\hline Comfortable environment & Patient ED categorizations & \\
\hline Availability of beds & Reduce waiting times & \multirow{2}{*}{ Service Cost } \\
\hline Good equipped area & Prompt service \\
\hline Layout of environment & Responsive staff \\
\hline \multirow{2}{*}{ Good expert triage person } & Faster admission to ED hospital \\
\cline { 2 - 2 } & Rapid Radiology / Labs results & \\
\hline
\end{tabular}

\section{Technical requirements identification}

Technical requirements, i.e., HOWs, are determined by a field visit survey. Three categories of ED participants have been regarded involving nurses, ED clinicians, and clinical engineers. A sample of ED stakeholders were drawn from 2 Egyptian hospitals ( $\mathrm{N}=134)$. Demographic analysis of ED stakeholders is introduced in Fig. 2.

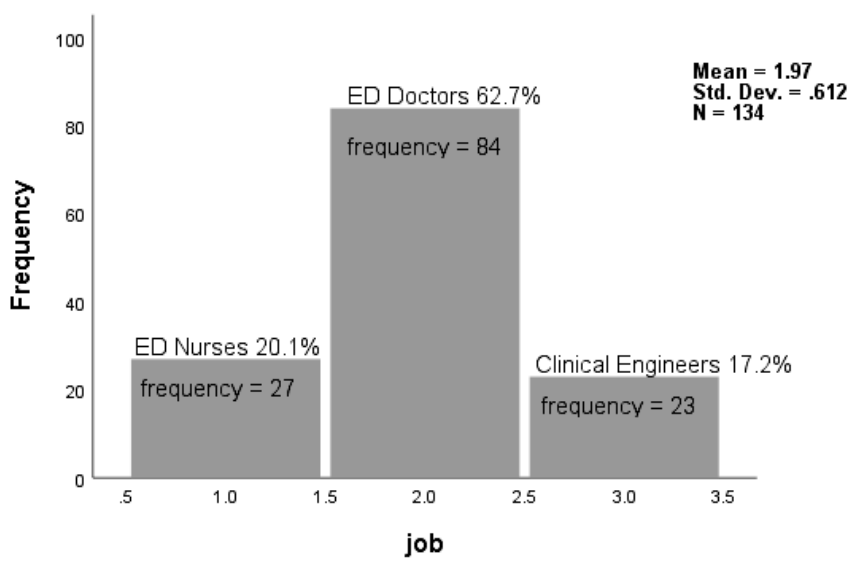

Fig. 2. Demographic analysis of ED stakeholders. 
The field visit survey was a questionnaire composed of 17 questions. It was conducted for three months through the investigated hospitals. The respondents were asked to answer the questions based on a Likert scale considering a 3-point scale (1- important and vital, 2- may be important, 3- not important or vital). By considering the answers of the respondents, the technical criteria were categorized into 2 main categories: human factors and design factors as illustrated in Table 2.

Table 2. List of technical requirements including human and design factors.

\begin{tabular}{|c|c|}
\hline Human factors (HF) & Design factors (DF) \\
\hline Training scale & Good bed management \\
\hline Guidelines and protocols & Well-equipped triage area \\
\hline $\begin{array}{l}\text { Rapid identification for patient } \\
\text { complaints }\end{array}$ & $\begin{array}{l}\text { Distance between ED and radiology/ } \\
\text { laboratories units }\end{array}$ \\
\hline Full medical history of patients & $\begin{array}{l}\text { Inter-and Intra-departmental } \\
\text { communications }\end{array}$ \\
\hline 8 hours of shift per day & Life supplement equipment \\
\hline Information from and to referring doctor & Centering nurse station \\
\hline Maintenance & Patient waiting room nearby triage area \\
\hline $\begin{array}{l}\text { Saving at least one nurse for } \\
\text { each } 2-3 \text { beds }\end{array}$ & \multirow{5}{*}{ Scheduled Ultrasound appointments } \\
\hline Using infection control rules & \\
\hline $\begin{array}{l}\text { Feedback regarding patients / staff } \\
\text { satisfaction (Questionnaire) }\end{array}$ & \\
\hline $\begin{array}{l}\text { Good communication with } \\
\text { patients/relatives }\end{array}$ & \\
\hline Quality assurance & \\
\hline
\end{tabular}

A total of 20 criteria were proposed, 12 for human factors and 8 for design factors. Pearson correlation bivariate test was carried out to indicate a correlation between the proposed technical criteria and the ED stakeholders (Valenta de Araujo et al., 2014). Figure 3 demonstrates the value of correlation coefficient $r$, which equals 0.190 . Theoretically, this positive value denotes a significant relationship between the 2 variables.

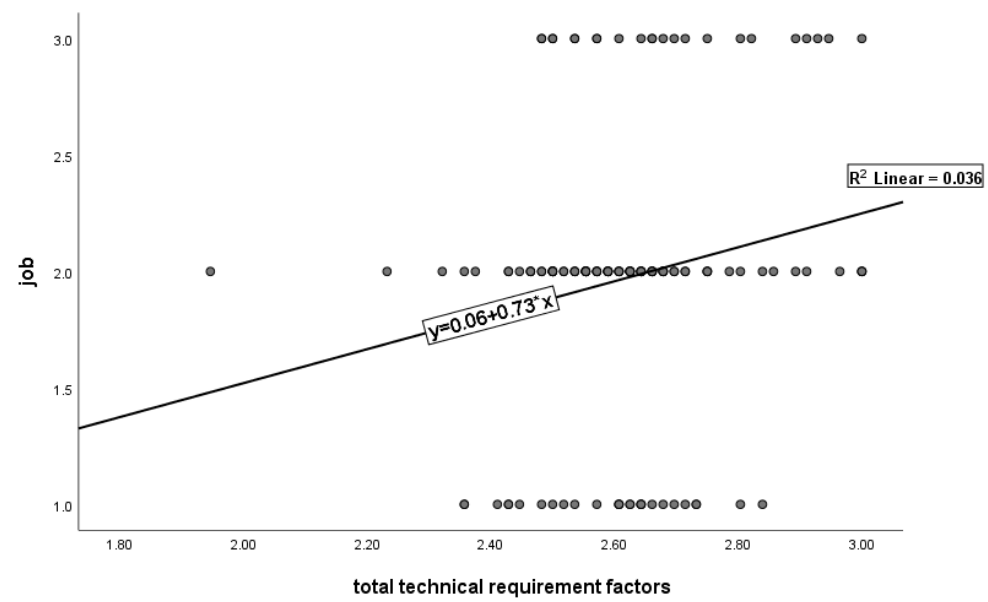

Fig. 3. Scatter plot showing a significant correlation between technical requirements and ED stakeholders under the survey. 


\section{Relationships between customer requirements and technical requirements}

According to rules of the QFD, the core of HoQ is a relationship matrix that maps WHATs items versus HOWs items. It maps strength of the relation that links each customer requirement with each technical requirement. Based on literature review, the adopted scale is 9 for strongly linked, 3 for moderately linked, 1 for weakly linked, and blank cells for no link (Akao et al., 2003). The relationship matrix of the proposed QFD is given in Fig. 4.

\section{Rating importance of customer requirements}

Rating importance of WHATs is a systematic mean to rank the customer requirements based on their weights to find out the most important factors that should be considered in the design. The weight of each requirement is explained in section 2. An illustrative example is given to understand how it is calculated. For instance, consider "availability of beds" criterion, by using 5-point scale: 4 was assigned for importance, 4 was for actual evaluation of customers, and 5 was put as a goal or target value. Hence, the improvement ratio is 1.25 (goal/actual evaluation), and the absolute weight is $5(1.25 \times 4)$. The relative weight is calculated by normalization, i.e., $(5 / 56) \times 100=8.9 \%$, where 56 is the total summation of all absolute weights.

\begin{tabular}{|c|c|c|c|c|c|c|c|c|c|c|c|c|c|c|c|c|c|c|c|c|}
\hline \multicolumn{21}{|c|}{ Technical requirement } \\
\hline 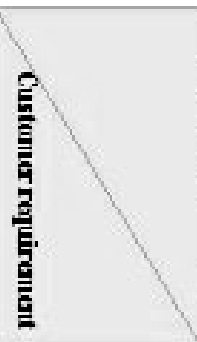 & 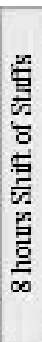 & 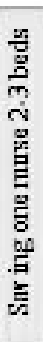 & 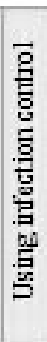 & 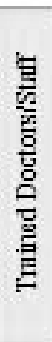 & 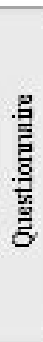 & 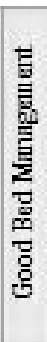 & 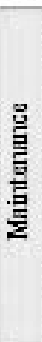 & 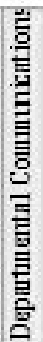 & 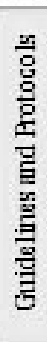 & 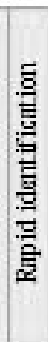 & 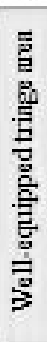 & 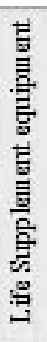 & 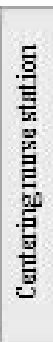 & 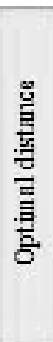 & 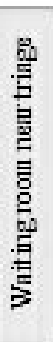 & 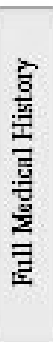 & 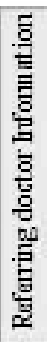 & 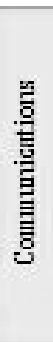 & 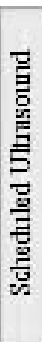 & 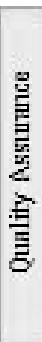 \\
\hline 24-Hour of Staff & 9 & 9 & 3 & 1 & 9 & & & 1 & & 1 & & & & & & & 1 & & & \\
\hline $\begin{array}{l}\text { Comfortable } \\
\text { environment }\end{array}$ & & & 9 & & & 9 & 9 & & 3 & & & & & & & & & 1 & & \\
\hline $\begin{array}{l}\text { Availability of } \\
\text { beds }\end{array}$ & & & & & & 9 & 1 & 3 & 9 & 3 & & & & & 1 & & & & & \\
\hline $\begin{array}{l}\text { Good equipped } \\
\text { Area }\end{array}$ & & & & & 3 & 1 & & & & & 9 & 3 & & & & & & & 1 & 3 \\
\hline $\begin{array}{l}\text { Layout Of } \\
\text { environment }\end{array}$ & & & 3 & & & 1 & & & & & & & 9 & 3 & 9 & & & & & 1 \\
\hline $\begin{array}{l}\text { Good triage } \\
\text { Person }\end{array}$ & & & & & & & & & 1 & 3 & 9 & & & & & 9 & & & & \\
\hline $\begin{array}{l}\text { Better Patient } \\
\text { Flow }\end{array}$ & & & & & 3 & & & & 9 & 1 & 9 & & & 9 & 3 & 1 & 3 & & & \\
\hline $\begin{array}{l}\text { Patient ED } \\
\text { Categorization }\end{array}$ & & & & 9 & 1 & & & & & 3 & & & & & & 9 & 9 & & & \\
\hline Reduce WT & 3 & 3 & & 9 & 1 & & & 1 & 9 & 9 & & 3 & & 3 & 1 & 1 & 9 & 3 & 3 & \\
\hline Prompt Service & 9 & 3 & & 1 & & & & & & 1 & 3 & 3 & 9 & 3 & & & 1 & & & \\
\hline ResponsiveStaff & 9 & 3 & & & 1 & & & & & & & & 1 & & & & 3 & 9 & & \\
\hline $\begin{array}{l}\text { Faster } \\
\text { Adrrission toED } \\
\text { hospital }\end{array}$ & & & & & & & 9 & 1 & 3 & & 1 & & & & & 9 & 1 & & & \\
\hline $\begin{array}{l}\text { Rapid } \\
\text { Radiology / Labs } \\
\text { results }\end{array}$ & & & & & & & & & 9 & & & 3 & & 9 & & & & & 9 & \\
\hline Service Cost & 3 & 3 & & 9 & & & 9 & & & & 3 & 3 & & & & & & & 1 & 9 \\
\hline
\end{tabular}

Fig. 4. Relationship matrix of the proposed QFD between the customer and the technical requirements to reduce the ED patient waiting time. 


\section{Roof and correlation matrix}

The roof matrix or a correlation matrix displays how technical requirements influence each other. The relationships are reported by symbols (Akao et al., 2003). The authors used the symbol (-) to imply strong negative correlation between two technical requirements; meanwhile, the symbol $(+)$ implies strong positive correlation between two technical requirements. Unlike those symbols, blank cell implies low or no correlation. Figure 5 depicts the correlation matrix illustrating an example of a correlation between " 8 hours shift of staff" criterion and the other criteria.

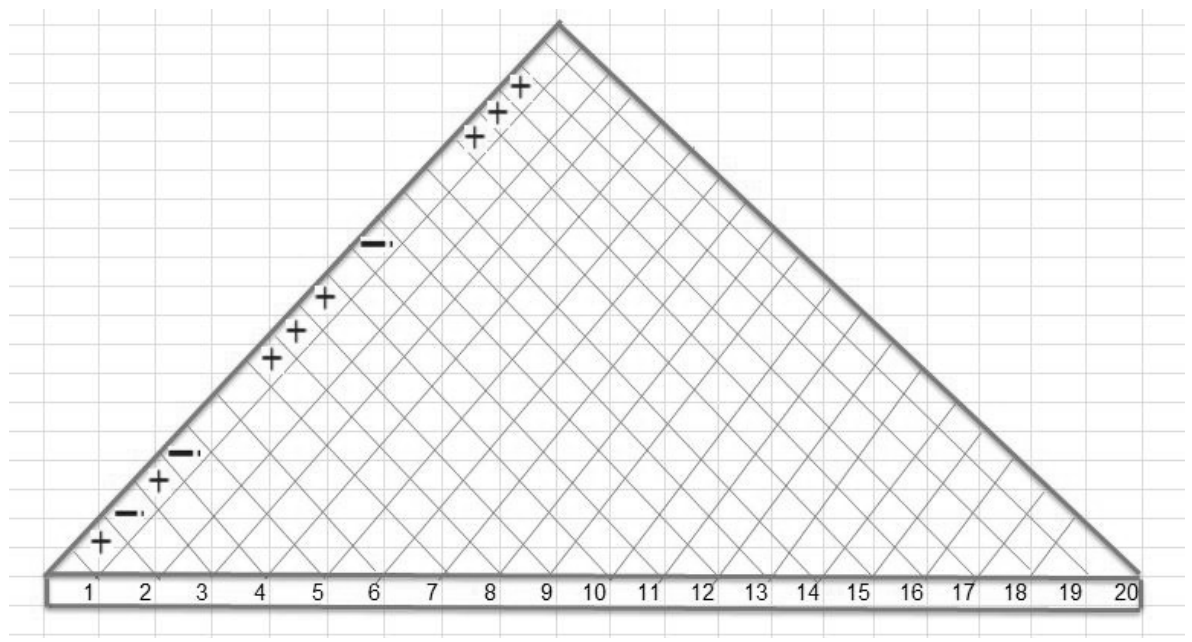

Fig. 5. The correlation matrix that illustrates a correlation between criterion $\# 1$ and the other technical criteria.

\section{Rating importance of technical requirements}

The output of HoQ is ranking of the technical requirements, i.e., HOWs. In order to rate the importance, we need to calculate the absolute weight for each requirement using (1). For example, the absolute weight of " 8 hours shift of staff" equals $(9 \times 7.14)+(9 \times 8.39)+(9 \times 8.39)+(3 \times 8.39)=241.07$. A similar approach is used to calculate the other absolute weights. The total summation of absolute weights is 3185.71 . By normalization, the relative weight is calculated, and each requirement is ranked. Accordingly, the relative weight of "8-hour shift of staff" is $7.57 \%$. The final framework of the proposed QFD is illustrated in Fig. 6. In addition, ascending ranking of the technical requirements is presented in Table 3.

In fact, due to the limited time of this research, only top ten criteria were considered for implementation. Furthermore, they were categorized into human factors and design factors. The human factors include guidelines and protocol, training, rapid identification for patients' complaints, 8-hour shift/staff, full medical history of patients, information from/to the referring doctor, and maintenance. On the other side, design factors incorporate well-equipped triage area, good bed management, and distance between radiology/laboratories units and ED. 


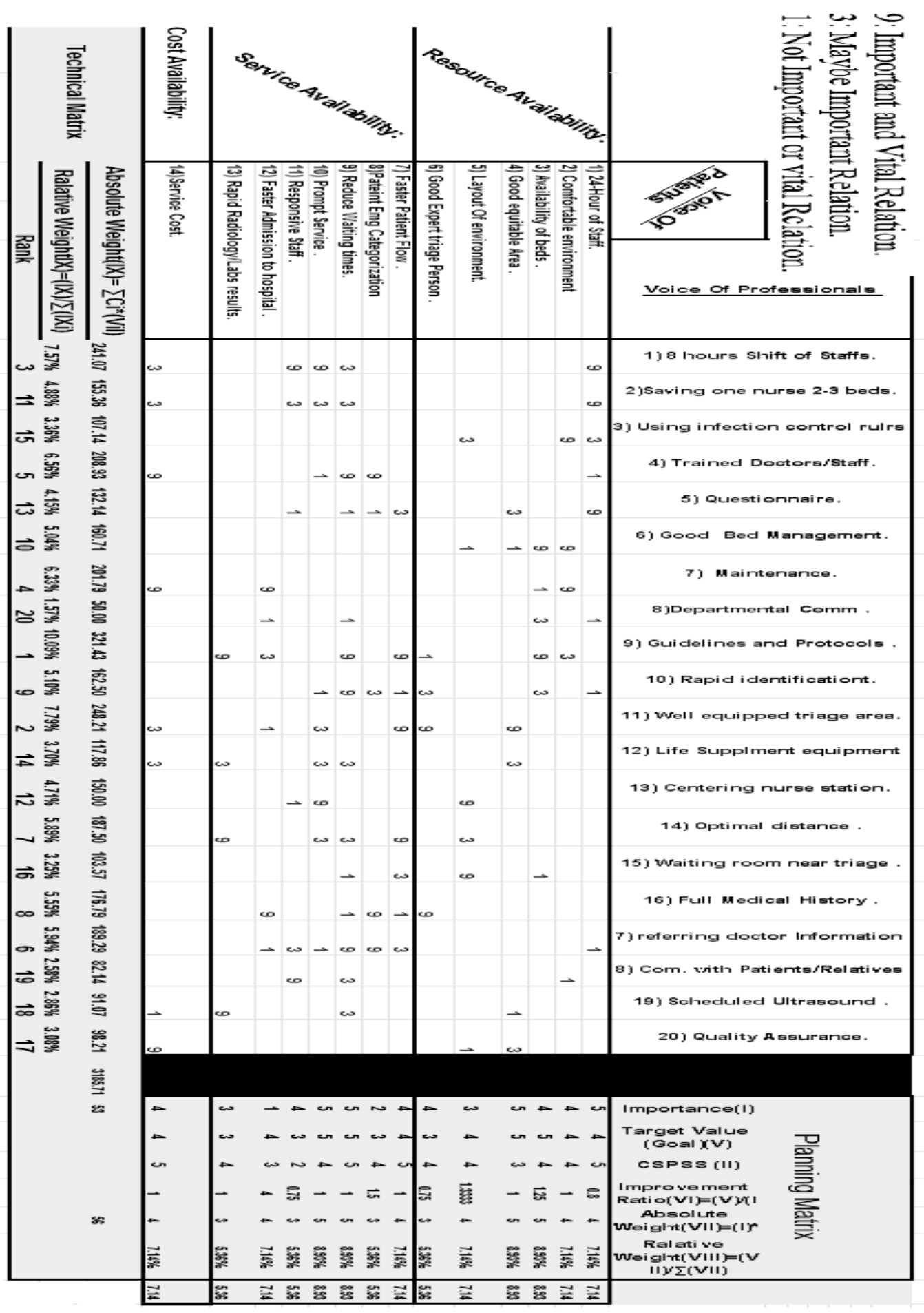

Fig. 6. The proposed QFD framework for reducing patient waiting time in the ED. 
Table 3. Ascending ranking of technical requirements of the proposed QFD.

\begin{tabular}{|l|l|}
\hline Technical Requirements of the purposed QFD & Rank \\
\hline Guidelines and Protocols & 1 \\
\hline Well-equipped triage area for each input patient & 2 \\
\hline 8-hour shift of staffs & 3 \\
\hline Maintenance & 4 \\
\hline Up to date trained staff & 5 \\
\hline Information from and to referring doctor & 6 \\
\hline Distance between ED and Radiology/ Labs & 7 \\
\hline Full Medical History of patients & 8 \\
\hline Rapid identification for patient complaints & 9 \\
\hline Good bed management & 10 \\
\hline Saving at least one nurse for each 2-3 beds & 11 \\
\hline Centering nurse station & 12 \\
\hline Feedback regarding patients / staff satisfaction (Questionnaire). & 13 \\
\hline Life supplement equipment & 14 \\
\hline Using infection control rules & 15 \\
\hline Patient waiting room nearby triage area & 16 \\
\hline Quality assurance & 17 \\
\hline Scheduled Ultrasound appointments & 18 \\
\hline Good communication with patients/relatives & 19 \\
\hline Inter-and Intra-departmental communications & 20 \\
\hline
\end{tabular}

\section{RESULTS}

Model verification takes place by comparing the importance rate of VoE versus output of the QFD. The average importance value of each requirement was evaluated by using the arithmetic mean, standard error of the mean, and standard deviation. The result of comparison is illustrated in Table 4. The result shows that the average error in the difference between the ranking of the VoE and the ranking of the QFD is 6.7 \pm 0.75 . This result implies a relatively difference between the 2 ranks. In explanation, the doctors and the nurses assigned weights to the factors related to the environment of work more than the other factors set by the QFD.

The model has been applied on a database that was collected from a governmental hospital and a private hospital in Egypt. In the governmental hospital, approximately 2500 patients have been recoded for one month in ED. The raw data was gathered from 12 am to $12 \mathrm{pm}$ in the first 2 weeks, while in the other 2 weeks it was collected from $12 \mathrm{pm}$ to $12 \mathrm{am}$. According to the UK triage scale (Mackway-Jones et al., 2006), patients were classified into 5 groups: A, B, C, D, and E. In implementation, patient's classification is clarified as shown in Fig. 7. The initial waiting times were noticed and reported for each group as illustrated in Table 5. Further, they were compared with maximum waiting times based on the British scale (Mackway-Jones et al., 2006). Indeed, model validation was carried out through application of the human factors and the design factors. 
Table 4. Comparisons between results of experts rank and the QFD rank.

\begin{tabular}{|c|c|c|c|c|c|}
\hline \multirow{2}{*}{$\mathbf{N}=\mathbf{1 3 4}$} & \multicolumn{2}{|c|}{ Mean } & \multirow{2}{*}{$\begin{array}{c}\text { Std. } \\
\text { Deviation }\end{array}$} & \multirow{2}{*}{ Rank } & \multirow{2}{*}{$\begin{array}{l}\text { QFD } \\
\text { Rank }\end{array}$} \\
\hline & Statistic & Std. Error & & & \\
\hline Shift of staff/doctors not exceed 8 hours & 2.659 & 0.026 & 0.30716 & 6 & 3 \\
\hline Saving one nurse for $2-3$ beds & 2.694 & 0.027 & 0.31938 & 5 & 11 \\
\hline Using infection control rules & 2.634 & 0.033 & 0.39339 & 9 & 15 \\
\hline Full medical history of patients & 2.855 & 0.029 & 0.34195 & 2 & 8 \\
\hline Guidelines and protocols & 2.625 & 0.026 & 0.30155 & 10 & 1 \\
\hline Rapid/Useful identification for patient complaints & 2.438 & 0.031 & 0.36330 & 17 & 9 \\
\hline Training (Up to date trained doctors/staff) & 2.574 & 0.031 & 0.36421 & 14 & 5 \\
\hline Information by and to referring doctor & 2.576 & 0.032 & 0.37575 & 13 & 6 \\
\hline Feedback regard to patients / staff satisfaction & 2.380 & 0.034 & 0.39873 & 19 & 13 \\
\hline Communications with patients/relatives & 2.624 & 0.033 & 0.38219 & 11 & 19 \\
\hline Maintenance & 2.641 & 0.024 & 0.28209 & 8 & 4 \\
\hline Inter- and Intra-departmental communications & 2.645 & 0.032 & 0.37207 & 7 & 20 \\
\hline Good bed management & 2.548 & 0.035 & 0.41071 & 15 & 10 \\
\hline Optimal distance between ED and Radiology/Lab & 2.457 & 0.033 & 0.38599 & 16 & 7 \\
\hline Well-equipped triage area & 2.833 & 0.027 & 0.32380 & 3 & 2 \\
\hline Patient waiting room nearby triage area & 2.615 & 0.041 & 0.47854 & 12 & 16 \\
\hline Centering nurse station. & 2.869 & 0.024 & 0.28050 & 1 & 12 \\
\hline Life supplement equipment & 2.429 & 0.042 & 0.49110 & 18 & 14 \\
\hline Scheduled ultrasound appointments & 2.35 & 0.059 & 0.686 & 20 & 18 \\
\hline Quality assurance & 2.80 & 0.038 & 0.438 & 4 & 17 \\
\hline \multicolumn{3}{|l|}{ Weighted Mean } & \multicolumn{2}{|c|}{2.6126} & \\
\hline \multicolumn{3}{|l|}{ Std. Deviation } & \multicolumn{2}{|c|}{0.15565} & \\
\hline
\end{tabular}

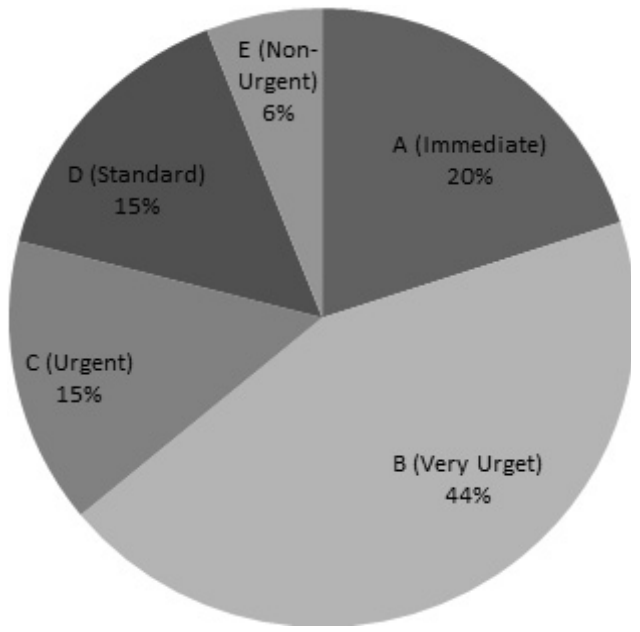

Fig. 7. Percentages of patients in the governmental hospital per month (2500 patients) for each patient group in ED. 
Table 5. Recorded patient waiting times based on their groups compared with the standard average time.

\begin{tabular}{|c|c|c|c|}
\hline $\begin{array}{c}\text { Patient } \\
\text { Type }\end{array}$ & Color code & $\begin{array}{c}\text { Standard Average Time } \\
\text { (minutes) }\end{array}$ & $\begin{array}{c}\text { Recorded Time } \\
\text { (minutes) }\end{array}$ \\
\hline A & Red & 2 & 10 \\
\hline B & Orange & 10 & $18-20$ \\
\hline C & Yellow & 60 & $70-80$ \\
\hline D & Green & 120 & $130-140$ \\
\hline E & Blue & 240 & $300-400$ \\
\hline
\end{tabular}

\section{Human factors' results}

All human factors have been applied to the governmental hospital except "maintenance" factor. The average waiting times were measured and reported to record the difference before and after application. Random numbers of each patient group were collected to make the comparison. Paired samples t-test is a parametric test that compares two means from the same individuals, objects, or related units (Thorlton et al., 2019). The two means typically represent two different times (e.g., pretest and posttest with an intervention between the two time points). Moreover, paired samples t-test correlation coefficients add information that waiting times before and after applying human factors are significantly positively correlated. The coefficients ( $r$ values) were $0.014,0.553,0.677,0.046$, and $0.093(\mathrm{p}<0.001)$ for groups A, B, C, D, and E, respectively. The summary of paired samples t-test is illustrated in Table 6.

Table 6. Paired samples t-test and correlation differences for average patients waiting times before and after application of human factors.

\begin{tabular}{|c|c|c|c|c|c|c|c|c|}
\hline & \multirow{3}{*}{ Patient Types } & \multicolumn{4}{|c|}{ Paired Samples Statistics } & \multirow{3}{*}{$\begin{array}{l}\text { Correl. } \\
\text { difference }\end{array}$} & \multirow{3}{*}{$\begin{array}{l}\text { Mean } \\
\text { differ. }\end{array}$} & \multirow{3}{*}{$\begin{array}{l}\text { Sig. diffe. } \\
\text { 2-tailed) }\end{array}$} \\
\hline & & \multicolumn{2}{|c|}{$\begin{array}{l}\text { Waiting time before } \\
\text { applying factors }\end{array}$} & \multicolumn{2}{|c|}{$\begin{array}{l}\text { Waiting time after } \\
\text { applying factors }\end{array}$} & & & \\
\hline & & Mean & $\begin{array}{c}\text { Std. } \\
\text { Deviation } \\
\end{array}$ & Mean & $\begin{array}{c}\text { Std. } \\
\text { Deviation } \\
\end{array}$ & & & \\
\hline $\mathbf{A}$ & Immediate & 6.05 & 0.917 & 3.24 & 0.52528 & 0.014 & 2.803 & 0.000 \\
\hline B & Very urgent & 18.73 & 4.933 & 12.21 & 2.42784 & 0.553 & 6.525 & 0.000 \\
\hline $\mathbf{C}$ & Urgent & 89.49 & 11.799 & 75.39 & 8.52969 & 0.677 & 14.093 & 0.000 \\
\hline D & Standard & 186.75 & 9.457 & 139.33 & 6.12685 & 0.046 & 47.425 & 0.000 \\
\hline $\mathbf{E}$ & Non-urgent & 257.75 & 4.320 & 248.58 & 7.86676 & 0.093 & 9.175 & 0.000 \\
\hline
\end{tabular}

The average waiting times before and after human factors are compared with average standard waiting times for patients' types as shown in Fig. 8. A significant improvement has occurred particularly for patients of type "E." In summary, when these factors were considered, the average waiting time was reduced as follows: $30 \%$ for type "A," $25 \%$ for type "B," $14 \%$ for type "C," $8 \%$ for type "D," and $16 \%$ for type "E." 


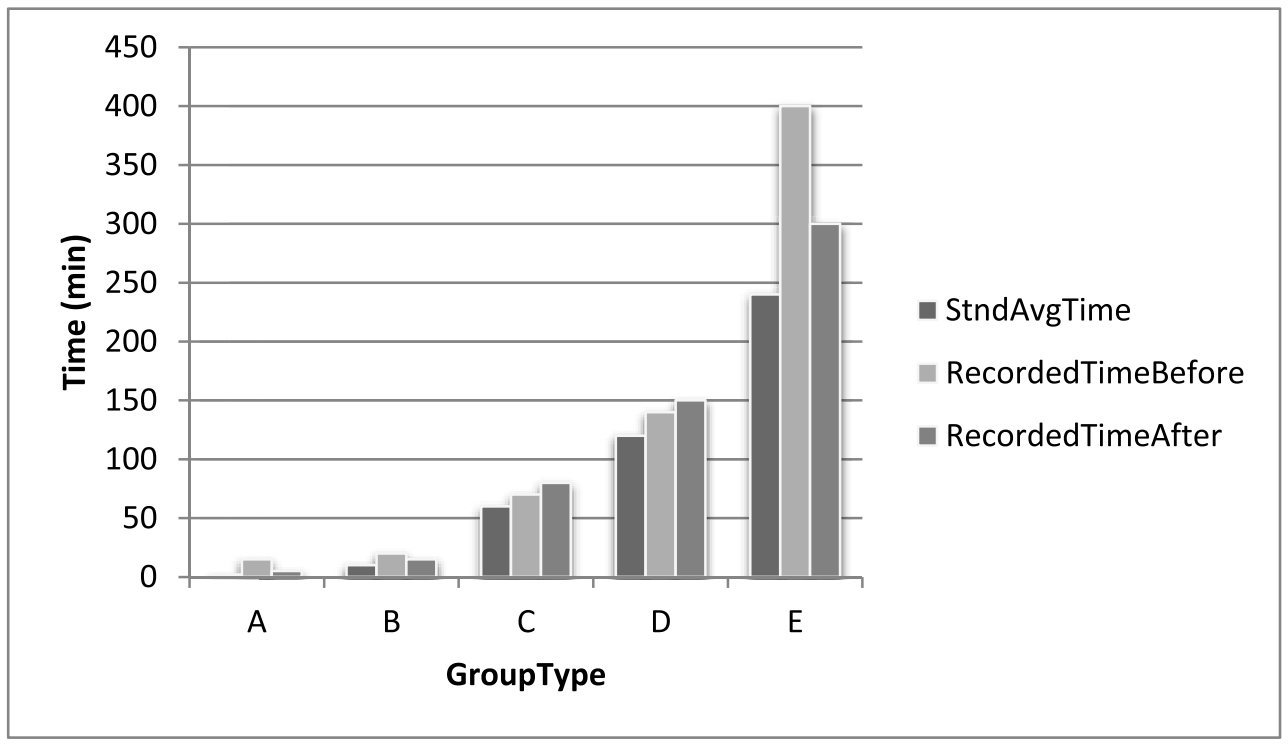

Fig. 8. Time recorded for patients in the governmental hospital before and after applying human factors compared with the standard average time.

\section{Design factors results}

Because the modification of the ED design is not allowed, design factors were applied by making a comparison between the investigated hospitals, the governmental and the private ones. Indeed, 2 different scenarios were permitted to monitor the impact of design factors. In addition, the term "maintenance" in human factors was considered in this comparison. It was compared in terms of the human resources, i.e., the biomedical engineers and the technicians, as well as existence of equipped workshop. The summary of the comparison is presented in Table 7.

Table 7. Design factors comparison of the governmental hospital versus the private hospital.

\begin{tabular}{|l|l|l|l|}
\hline \multirow{2}{*}{ Design Factors } & Items & $\begin{array}{l}\text { Governmental } \\
\text { Hospital }\end{array}$ & $\begin{array}{l}\text { Private } \\
\text { Hospital }\end{array}$ \\
\cline { 2 - 4 } & No. of patients/day & $400-500$ & $5-8$ \\
\hline \multirow{2}{*}{ ED \& radiology/labs } & Distance (Meter) & 1000 & 20 \\
\cline { 2 - 4 } Good Bed Management & Time (min) & 10 & 2 \\
\hline \multirow{2}{*}{ Well-equipped triage area rooms } & 4 & 6 \\
\cline { 2 - 4 } & No. of beds & 20 & 6 \\
\hline & $\begin{array}{l}\text { Life supplement } \\
\text { equipment }\end{array}$ & $\begin{array}{l}\text { - No ultrasound } \\
\text { - No Ventilator }\end{array}$ & $\begin{array}{l}1 \text { ultrasound } \\
1 \text { ventilator }\end{array}$ \\
\hline
\end{tabular}

As shown in Table 7, the distance between ED and the served departments, i.e., radiology/laboratories in the private hospital, is longer than that in the governmental one. Consequently, more time is consumed by patients (10 min vs. $2 \mathrm{~min}$ ). For good bed management factor, the number of the beds in the private hospital is adequate and fits the number of the patients (bed per patient). In contrast, for the other one, the number of the beds is often in shortage, i.e., 20 patients per bed. Thus, a long waiting time is spent by patients to have a bed. Moreover, beds distribution should be assigned appropriately to facilitate patient flow in order to reduce the waiting time. A triage is a vital area to admit 
ED patients. It should be adequately equipped to serve the patients appropriately. As noted in the private hospital, a ventilator and an ultrasound machine are provided in the triage area, which implies less waiting time. In conclusion, recorded waiting times in the private hospital are competitive and less than the governmental hospital, and they do not exceed the standard average waiting time as shown in Fig. 9.

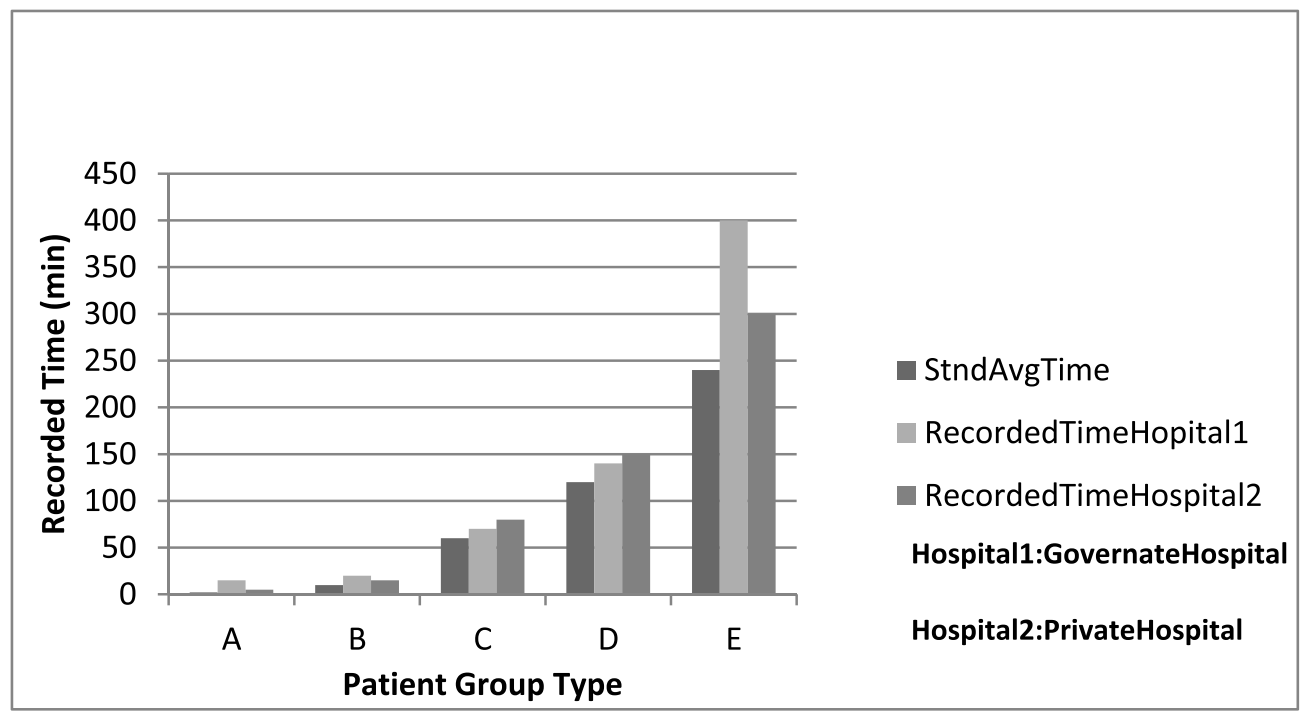

Fig. 9. Initial waiting times for the governmental hospital and the private hospital compared against the standard average time.

\section{DISCUSSION}

The study highlights significant factors that could influence patient waiting time in the ED. Through application of the QFD, these factors have been weighted to be prioritized. All ED stakeholders are involved to conclude the beneficial factors. According to the experience, the voice of engineers was classified into human factors and design factors. By implementing the most significant factors on 2 different hospitals, the impact on patient waiting time has been recognized. Indeed, human factors are more applicable in the real environment. However, "maintenance" factor is not easy to be measured. Therefore, it is evaluated only in terms of human resources and equipped workshops. Further, in early planning of hospital design, if the recommended design factors are considered, patient flow and consequently patient waiting time would be enhanced.

By considering the ED stakeholders, the authors proposed new factors to be measured. For instance, following "guidelines and protocols" is an extremely important issue to be implemented in the ED. Thus, classifying ED patients into five groups has reduced the waiting time. Also, consider that the "distance between ED and radiology/laboratories units" has its consequence on patient flow and waiting time. Moreover, the medical equipment is complementary to medical staff. Therefore, different forms of medical equipment, "maintenance" and "well-equipped triage area," are regarded in the ED. On the other side, the schedule of staff and/or nurses allocation within the ED is assumed to be a dominant factor. Most of studies adopt staff schedule for improving ED services. As such, the study reveals other dominant factors that should be regarded in resolving the ED overcrowding problem.

Regarding the results of this study, we can recognize the difference between them and those of other studies. Most of them, if not all, did not consider the ED patient category. Moreover, based on the British scale, standard average waiting time for each patient category was regarded as a reference for comparison. Further, there is a noticeable difference in reducing the average waiting time (10\% to 40\%) compared with others. In the study of QIP (Chen-Mei et al., 2019), it was 3.7\%. Also, Paul and Lin (Paul et al., 2012) succeeded in improving LOS by $18 \%$. In another work 
(Al-Refaie et al., 2014), patient waiting time has been reduced by $7 \%$ approximately. Ahmed and Alkhamis (Ahmed et al., 2009) have proved that optimizing the staff allocation in ED improved the patient throughput by $28 \%$.

The application of the QFD is rarely adopted in healthcare issues (Gremyr et al., 2013). To the best of our knowledge, for first time, the QFD model is proposed to improve patient waiting time in the ED. There are 2 studies that were conducted in the ED using the QFD approach. Two different points of view were regarded. In one study (Buttigieg et al., 2016), the QFD was utilized to improve the quality of ED medical services in a Maltese hospital. The model identified critical processes that were required to be enhanced in the ED. The processes include patient admission, patient circulation, staff allocation, and preparation of triage area. In another context, the QFD has been used to improve only the design of ED by employing different scenarios (Abdelsamad et al., 2018).

\section{CONCLUSION}

Quality function deployment has been adopted for first time to resolve the problem of ED overcrowding. The study concerns patient waiting time in ED as one of the leading causes of overcrowding. By considering the principles of the QFD, a field visit questionnaire was carried out to involve the stakeholders. According to the customer (patient) requirements, the technical requirements are classified into human factors and design factors. The role of QFD is to give a reasonable weight to each factor to be oriented for reducing the waiting time. Guidelines and standards appear as a dominant factor that should be put in mind to reduce the waiting time. One form of employing ED guidelines is to classify patients into groups relying on their clinical status.

Further, some criteria, which are negligible from the stakeholders, were highlighted by the QFD. For example, the distance between radiology/laboratories and ED is a vital issue, as well as staff training. In contrast, some factors were given high priority regardless their importance rate such as centering nurse station and communication with patient/relatives. Moreover, early planning of the ED should consider patient flow and layout of the served units like radiology/laboratories departments. The QFD model has proved its robustness in reducing waiting times for different types of patients. Obviously, reducing patient waiting time is influential on ED functional operations and expenditures. The QFD adds value to the healthcare system by reducing the patient waiting time and consequently increasing the served patients and improving the service quality in the ED.

In general, for any healthcare facility, the study reveals the improved ED processes that should be adopted to reduce patient waiting time. According to our results, the ED system should start with classification of the ED patients relying on their emergency. At this point, triage area is the first admission point, so it should be highly equipped with the necessary medical equipment and qualified medical staff. In fact, the medical staff is the main core of the ED; accordingly, they should be updated with continuous training. Further, 3 shifts are recommended to a void staff fatigue that certainly impact patient treatment. Medical equipment is complementary to the ED staff. Thus, required equipment should be supplied in the ED, and it should be in a good condition as well. In addition, information plays a vital role in the ED system; therefore, history of the patients should be recorded. It facilitates patient tracking in admission, treatment, and discharging. Finally, patient flow should be arranged in a way that minimizes patient circulation within the ED. It could be done by regarding distances between entrances, waiting areas, treatment rooms, and other served units such as laboratories.

\section{REFERENCES}

Abdelsamad, Y., Rushdi, M. \& Tawfik, B. 2018. Functional and spatial design of emergency departments using quality function deployment. Journal of Healthcare Engineering, 2018: 1-8.

Adel, H., Abdel Wahed, M. \& Saleh, N. 2018. A novel approach for improving patient flow in emergency department. Proceeding of the 9th Cairo International Biomedical Engineering Conference (CIBEC), Cairo, Egypt.

Ahmed, M.A. \& Alkhamis, T.M. 2009. Simulation optimization for an emergency department healthcare unit in Kuwait. European Journal of Operational Research, 198: 936-942.

Akao, Y. \& Mazur, G.H. 2003. The leading edge in QFD: past, present, future. International Journal of Quality \& Reliability 
Management, 20:20-35.

Al-Refaie, A., Fouad, R.H. \& Li, M-H. 2014. Applying simulation and DEA to improve performance of emergency department in a Jordanian hospital. Simulation Modeling Practice and Theory, 41: 59-72.

Bennur, S. \& Jin, B. 2012. A conceptual process of implementing quality apparel retail store attributes: an application of Kano's model and the uality function deployment approach. International Journal of Business Humanities and Technology, 2(1): 174-183.

Buttigieg, S.C., Dey, P.K. \& Cassar, M.R. 2016. Combined QFD and the LFA to improve quality of care in Malta. International Journal of Healthcare Quality Assurance, 29(2): 123-140.

Chen-Mei, H., Li-Lin L. \& Yun-Te, C. 2019. Emergency department overcrowding: quality improvement in a Taiwan medical center. Journal of the Formosan Medical Association, 118: 186-193.

Dehe, B. \& Bamford, D. 2017. Quality function deployment and operational design decisions-a healthcare infrastructure development case study. Production Planning \& Control, 28(14): 1177-1192.

Delegado, D.J., Bampton, K.E. \& Aspinwall, E. 2007. Quality function deployment in construction. Construction Management and Economics Journal, 24(4): 597-609.

Gilmore, T., Krantz, J. \& Ramirez, R. 1986. Action based modes of inquiry and the host-researcher relationship. Consultation: An Integrated Journal, 5(3): 160-176.

Gremyr I. \& Raharjo H. 2013. Quality function deployment in healthcare: a literature review and case study. International Journal of Healthcare Quality Assurance, 26(2): 135-146.

Mackway-Jones, K., Marsden, J. \& Windle, J. 2006. Emergency triage: Manchester triage group, 2nd Edition, Blackwell Publishing.

Paul J.A. \& Lin, L. 2012. Models for improving patient thoughput and waiting at hospital emergency departments. The Journal of Emergency Medicine, 43(6): 1119-1126.

Saleh, N., Sharawi, A., Abdel Wahed, M., Petti, A., Puppato, D. \& Balestra, G. 2015. Preventive maintenance prioritization index of medical equipment using quality function deployment. IEEE Journal of Biomedical and Health Informatics, 19(3): 1029-1035.

Thorlton, J. \& Catlin, A.C. 2019. Data mining for adverse drug events: impact on six learning styles. Comput Inform Nurs., 37(5): 250-259.

Valenta de Araujo, R., Martinz, L. \& Moreira, F.A. 2014. Statistical analysis of the relationship between payment behavior variables and delinquency in electricity consumption. Proceeding of IEEE PES Transmission \& Distribution Conference and Exposition, Latin America.

Zeng, Z., Ma, X., Hu, Y. \& Li, J. 2012. A simulation study to improve quality of care in emergency department of a community hospital. J Emerg Nurs, 38(4): 322-328. 